\title{
O PAPEL DE POLÍTICAS PÚBLICAS NA FORMAÇÃO DE CAPITAL SOCIAL: O CASO DA ASSOCIAÇÃO DOS PRODUTORES RURAIS DE ESTÂNCIA VELHA/RS
}

\author{
Igor Silva de Bearzi ${ }^{1}$ \\ José Odelso Schneider ${ }^{2}$
}

\begin{abstract}
RESUMO
O presente estudo visou contribuir para a discussão sobre a relação entre Estado e formas associativas ou cooperativas, a partir da análise do papel desempenhado por uma política pública, o Programa Nacional de Alimentação Escolar (PNAE), na constituição de uma associação com personalidade jurídica, a Associação dos Produtores Rurais de Estância Velha (APREV). Trabalhou-se para levantar evidências que pudessem explicar a dinâmica do processo de formação de capital social estimulado pela política pública, ou seja, a formação do grupo em que se constitui a associação. Esta pesquisa localiza-se no universo das pesquisas qualitativas, utilizando como técnicas para coleta das informações a pesquisa documental, pesquisa bibliográfica, observação participante e entrevistas semiestruturadas. A análise dos resultados indicou que os agricultores associados na APREV aproximaram-se e consolidaram relações que permitiram que participassem no PNAE em Estância Velha, apesar dos relutantes comportamentos individualistas e egoístas. Foi identificado também que esta atitude interessada dos agricultores em associar-se demonstra a importância de estímulos à cooperação, dentre os quais, os promovidos pelo Estado.
\end{abstract}

Palavras Chave: associativismo, capital social, comportamento humano, cooperativismo.

\section{THE ROLE OF PUBLIC POLICIES IN THE SHAPING OF SOCIAL CAPITAL: THE CASE OF ESTÂNCIA VELHA/RS CITY'S ASSOCIATION OF RURAL PRODUCTERS}

\begin{abstract}
The present study tried do cast light upon the discussion involving the State as well the associative and cooperative procedures, from the analysis of the function carried out by a public policy - The National Program of School Nutriment (PNAE) under a legal and judicial association. The Association of Rural Products in the community of

\footnotetext{
Graduado em Agronomia (UFSM). Especialista em Cooperativismo (UNISINOS). E-mail: igor.de.bearzi@gmail.com

${ }_{2}^{2}$ Graduado em Sociologia Política pela Pontífica Universidade Católica do Rio de Janeiro (PUC-RJ). Mestre em Ciências Del Desarrollo pelo Instituto Latinoamericano de Doctrina y Estudios Sociales. Doutor em Ciências Sociais pela Pontífica Universidade Gregoriana de Roma. Docente no Programa de Pós-Graduação em Ciências Sociais da Universidade do Vale do Rio dos Sinos (UNISINOS). E-mail: odelso5@gmail.com
} 
Estancia Velha (APREV), trying to raise evidence able do explain the dynamic process of generating the social funds prompted through the public policy, in other words, shaping the group of the association itself. This research is located in the universe of qualitative research, using as techniques for collecting the information, documentary research, bibliographic research, participant observation and semi-structured interviews. The analysis of the results indicated that the farmers associated in the APREV approached and consolidated relationships that allowed them to participate in the PNAE in Estância Velha, despite the reluctant individualistic and selfish behaviors. Also it was noticed that this attitude of the formers interested in association, closely in order to show the relevance of the comparison related, with those who are being advanced by the State.

KEY WORDS: associativism, cooperativism, human attitude. social capital.

\section{INTRODUÇÃO}

O presente estudo visou contribuir para uma discussão que marca o cooperativismo desde a sua origem, um amplo, profundo e polêmico debate sobre a relação entre Estado e formas associativas ou cooperativas. Resguardadas as proporções e limitações, o estudo buscou analisar o papel desempenhado por uma política pública, o Programa Nacional de Alimentação Escolar (PNAE), na constituição de uma associação com personalidade jurídica, a Associação dos Produtores Rurais de Estância Velha (APREV).

A importância dessa temática está na identificação de uma correlação positiva entre a existência de organizações cooperativas e associativas e índices de desenvolvimento econômico e de qualidade de vida. Tal percepção justificou significativas iniciativas do Estado que buscaram incentivar a organização, o que reforça a importância de esforços teóricos que identifiquem as possibilidades, dificuldades e limitações de experiências associativas.

A principal abordagem teórica que embasou o estudo foram as elaborações sobre Capital Social de Pierre Bourdieu (1996; 1998), pois foi discutido o papel do PNAE na construção ou consolidação de "redes duráveis de relações", ou seja, capital social na abordagem Bourdieana. Obras de teóricos precursores do cooperativismo como Louis Blanc (2002) já discutiam o assunto, reivindicando a presença do Estado no impulso inicial de organizações cooperativas. Mais recentemente, indo ao encontro de Blanc, Evans (2004), considera "central as políticas públicas nos processos de mudança social", afirmando que o Estado seria capaz de mobilizar os recursos iniciais da comunidade, promovendo a concertação social e gerando bem-estar social.

Por outro lado, Schneider (2012) resgatou o princípio da autonomia e independência do cooperativismo, contudo, afirmou também que "o cooperativismo aceita e, às vezes, até reclama a colaboração do poder público, mas desde que o respeite na sua especificidade e autonomia". As discussões e experiências cooperativas indicam que este é um debate necessário, haja vista as vantagens que podem ser auferidas a empreendimentos cooperativos a partir dos estímulos do Estado, assim como as circunstâncias criadas a partir de normas, incentivos, ingerências e restrições que, não raro, conduziram a vícios e fracassos de experiências cooperativas.

Segundo Grisa e Schneider (2015), foi criado um conjunto de novas políticas públicas de desenvolvimento rural direcionadas para os agricultores familiares a partir das novas relações entre Estado e Sociedade Civil inauguradas desde a Constituição de 1988. Os autores identificaram três gerações de políticas, a primeira com uma 
característica agrícola e agrária, a segunda com um cunho mais social e assistencial e a terceira geração mais centrada na segurança alimentar e na sustentabilidade ambiental. O Programa Fome Zero inaugurou esta terceira geração ressaltando o potencial dos mercados institucionais no fortalecimento da agricultura familiar, promovendo mudanças no PNAE a partir da Lei 11.947/09 (de agora em diante, denominada Lei do PNAE), a qual garantiu que uma parcela do mercado das compras institucionais de alimentos pelas escolas fosse reservada para os agricultores familiares, seus empreendimentos ou organizações.

No âmbito de algumas políticas públicas de desenvolvimento rural implementadas pelo Governo Federal identificou-se uma intencionalidade em promover a organização associativista e cooperativista. A Lei do PNAE estabeleceu que "do total dos recursos financeiros repassados pelo Fundo Nacional de Desenvolvimento da Educação (FNDE), no âmbito do PNAE, no mínimo 30\% deverão ser utilizados na aquisição de gêneros alimentícios diretamente da agricultura familiar e do empreendedor familiar rural ou de suas organizações", e a Resolução $n^{\circ}$ 26/2013/FNDE estabeleceu as normas de execução do PNAE.

A forma de aquisição dos alimentos da agricultura familiar estabelecida pela resolução dispensa licitação, devendo ser realizada mediante Chamada Pública, procedimento diferenciado onde os preços devem ser condizentes com os praticados no mercado. Contudo, há uma priorização de propostas segundo determinados critérios de desempate, dentre os quais, o que prioriza os fornecedores locais e a aquisição dos alimentos de agricultores familiares organizados em grupos formais (possuidores de CNPJ), sobre os grupos informais e, destes, sobre agricultores que se coloquem no certame individualmente. Com isso, a APREV apresenta-se na concorrência da Chamada Pública do PNAE em Estância Velha em condição vantajosa em relação aos fornecedores de outros municípios ou aqueles não organizados em instituições com personalidade jurídica.

Entende-se que a existência, o acúmulo ou formação de redes duráveis de relações permanentes e úteis é um possível fator que justifica os êxitos de experiências associativas e cooperativas. Neste sentido, este estudo se propôs a investigar a seguinte questão: Qual foi o papel do PNAE na formação de capital social expresso na aproximação, consolidação ou distanciamento das relações estabelecidas entre os agricultores familiares sócios na APREV?

\section{REVISÃO DE LITERATURA}

Nas duas próximas seções trazemos a contribuição de alguns autores e suas teorias para embasar a constituição de uma análise que possa explicar também teoricamente a experiência da formação de capital social expressa, neste caso, na constituição da associação. No primeiro deles trazemos teorias sobre o comportamento humano que entendemos que tangenciam e trazem importantes implicações na formação de grupos, o que entendemos ser necessário para a discussão sobre os êxitos e desafios que estão postos à construção associativista e cooperativista. Na segunda seção é abordado o tema do capital social propriamente dito, trazendo elementos para discutirmos mais adiante sobre a importância de políticas públicas na formação de "redes duráveis de relações", visando a constituição de laços de solidariedade e a promoção da prática da cooperação, que são indispensáveis na construção associativista e cooperativista. 


\subsection{O COMPORTAMENTO HUMANO: DA CONSTRUÇÃO INDIVIDUALISTA À EDUCAÇÃO COOPERATIVISTA}

As diferentes formas de relação social mantidas na produção e reprodução da vida humana compõe um elemento central na explicação do desenvolvimento de diferentes sociedades, ou então, da história de desenvolvimento de uma dada sociedade. O modo de produção hegemônico no mundo atual, o capitalismo, é caracterizado por quatro conjuntos de esquemas institucionais e comportamentais: 1) produção de mercadorias orientada pelo mercado, 2) propriedade privada dos meios de produção, 3) um grande segmento da população que não pode existir a não ser que venda sua força de trabalho no mercado e 4) comportamento individualista, aquisitivo, maximizador, da maioria dos indivíduos dentro do sistema econômico (HUNT, 2013).

Considerado o primeiro economista a formular uma teoria abstrata, completa e coerente sobre o capitalismo, Adam Smith (1723 - 1790) introduz a noção de autointeresse, que seria "[...] um sentimento natural ao ser humano [...] significa apenas que cada pessoa deve saber o que é melhor para si [...] quando dirigido para assuntos econômicos, o autointeresse bem dosado se converteria na virtude da prudência" (BIANCHI; SANTOS, 2005). Em A Riqueza das Nações (1776), Smith afirma que "[...] Cuidando do seu próprio interesse, o indivíduo, quase sempre, promove o interesse da sociedade mais eficientemente do que quando realmente deseja promovê-lo", o que pode ser considerado uma teoria que se opõe às elaborações que afirmam a importância da solidariedade, da ajuda mútua e da reciprocidade na sociedade (HUNT, 2013).

Contudo, contemporâneos a Smith nos debates entre os chamados clássicos, existem teorias que questionam a afirmação de que o homem autointeressado e egoísta é um comportamento intrínseco à natureza humana, uma moral pertencente existência humana. Segundo Paulani (2005), autores como Karl Marx escreveram que a forma de pensar dos indivíduos está associada à realidade em que ele está inserido. Nesta perspectiva, a consciência dos seres humanos seria uma construção social. Paulani (2005) resgata a percepção de Marx quanto a formação do modo de vida dos homens, expressa por este da seguinte forma:

\footnotetext{
"Pode-se distinguir os homens dos animais pela consciência, pela religião ou por tudo que se queira. Mas eles próprios começam a se diferenciar dos animais tão logo começam a produzir seus meios de vida (...) O modo pelo qual os homens produzem seus meios de vida depende, antes de tudo, da natureza dos meios de vida já encontrados e que têm de reproduzir. Não se pode considerar tal modo de produção sob um único ponto de vista, a saber, a reprodução da existência física dos indivíduos. Trata-se muito mais de (...) determinada forma de manifestar sua vida, determinado modo de vida dos mesmos." (PAULANI, 2005, p.12)
}

Bourdieu (1996) escreveu que é preciso cuidar para não tomar como intrínsecas aos agentes ou aos grupos, propriedades que ocorrem em um momento dado, a partir de uma dada posição em um "[...] espaço social determinado e em uma dada situação de oferta de bens e práticas possíveis". Para o autor, o espaço social aglutina um conjunto de posições ou classes de posições distintas e coexistentes, "definidas umas em relação às outras por sua exterioridade mútua e por relações de proximidade, de vizinhança ou de distanciamento e, também, por relações de ordem, como acima, abaixo e entre", cujas posições são categorizadas a partir de dois 
princípios de diferenciação. Como exemplo, o autor traz a realidade de uma nação desenvolvida como os Estados Unidos, onde os princípios de diferenciação no espaço social mais eficientes seriam a do capital econômico e do capital cultural, o que indica que os agentes têm tanto mais em comum quanto mais próximos estejam nestas duas dimensões. Bourdieu (1996) introduz um conceito importante para a compreensão das diferentes manifestações práticas dos agentes ou de classes construídas como agentes, o conceito de habitus. $O$ autor afirma que:

\begin{abstract}
"A cada classe de posições corresponde uma classe de habitus (ou de gostos) produzidos pelos condicionamentos sociais associados à condição correspondente e, pela intermediação desses habitus e de suas capacidades geradoras, um conjunto sistemático de bens e de propriedades, vinculadas entre si por uma afinidade de estilo. [..] O habitus é esse princípio gerador e unificador que retraduz as características intrínsecas e relacionais de uma posição em um estilo de vida unívoco, isto é, em um conjunto unívoco de escolhas de pessoas, de bens, de práticas." (BOURDIEU, 1996, p. 21 -22)
\end{abstract}

Os condicionamentos identificados por Bourdieu repercutem na opção dos agentes em vincular-se a grupos ou não, pois um fator determinante da possibilidade e opção dos agentes para construir redes duráveis de relações diz respeito à proximidade destes no espaço geográfico ou no ambiente econômico e social. Para os defensores do cooperativismo, a cooperação é um comportamento ideal e superior ao ideal liberal, cujas atitudes, valores, normas, princípios e metodologia precisam ser construídos através da educação cooperativa. Segundo Schneider (2003), as pessoas nascem e vivem numa sociedade guiada pelo individualismo e pela concorrência, o que impõe às organizações associativas e cooperativas a necessidade vital de educar para a cooperação visando a formação de uma conduta solidária, participativa, que pratique a ajuda mútua.

\title{
2.2. A FORMAÇÃO DE CAPITAL SOCIAL E O PROCESSO DE CONSTRUÇÃO ASSOCIATIVISTA
}

No espaço social em que vivem os agentes, a vinculação a grupos traz consigo forças potenciais que podem vir a possibilitar a realização de objetivos, dentre os quais, a formação associativa e cooperativa. As relações estabelecidas entre os agentes na formação de grupos, ou de capital social, é objeto de investigação e motivou importantes elaborações. Correa (2003) identifica semelhanças nas abordagens sobre capital social feitas pelos autores Coleman, Woolcock e Putnam, que o identificam "como uma construção de organização social - confiança, normas e redes de relacionamento". Segundo o autor, Putnam e Coleman relacionam Capital Social com o sentido de comunitarismo, não relacionado a valor de mercado ou utilitarismo: "Trata-se de um valor da comunidade, gerador de bens públicos, onde todos se beneficiam". Segundo Costa e Costa (2005), Bourdieu, Coleman e Putnam convergem ao afirmar que capital social é um recurso que pode ser acumulado. Uma particularidade do capital social é que ele se configura como um bem público, somente podendo ser acumulado mediante a manutenção e ampliação das relações sociais que ocorrem a nível de comunidade. Neste estudo, privilegiamos a abordagem sobre capital social elaborada por Bourdieu, cujo enfoque está na existência de redes duráveis de relações permanentes e úteis. Segundo o autor, capital social pode ser definido como: 
"[...] conjunto de recursos atuais ou potenciais que estão ligados à posse de uma rede durável de relações mais ou menos institucionalizadas de interconhecimento e de interreconhecimento ou, em outros termos, à vinculação a um grupo, como conjunto de agentes que não somente são dotados de propriedades comuns (passíveis de serem percebidas pelo observador, pelos outros ou por eles mesmos), mas também são unidos por ligações permanentes e úteis." (BOURDIEU, 1998, p. 67)

Bourdieu (1998) também escreve que os agentes possuidores do capital social necessariamente devem manter relações de proximidade geográfica ou no espaço econômico e social, por que as ligações "são fundadas em trocas inseparavelmente materiais e simbólicas cuja instauração e perpetuação supõem o reconhecimento dessa proximidade". Portanto, Bourdieu estabelece como questão central a sua teoria à vinculação a uma "rede durável de relações", e defende que tanto maior será o volume de capital social de um agente ou grupo de agentes quanto maior for a rede de relações que pode mobilizar e quanto maior for a quantidade de capitais (econômico, cultural ou simbólico) possuído por esses agentes com quem se relaciona.

Bourdieu escreve que "os lucros que o pertencimento a um grupo proporcionam estão na base da solidariedade que os torna possível", lucros materiais, como toda espécie de serviços, ou simbólicos (BOURDIEU, 1998). Noutra obra deste autor, define-se capital simbólico como uma propriedade qualquer que pode ser percebida e reconhecida pelos agentes, como, por exemplo, a honra, o prestígio, os direitos juridicamente instituídos, portanto, que remetem também a valores, a cultura, sendo o Estado o lugar por excelência para impor e inculcar os "princípios duráveis de visão e de divisão" (BOURDIEU, 1996).

Para Bourdieu (1998), a existência de capital social não é um dado natural nem social, instituído de uma vez por todas e para sempre, "mas o produto do trabalho de instauração e de manutenção que é necessário para produzir e reproduzir relações duráveis e úteis, aptas a proporcionar lucros materiais ou simbólicos". Portanto, os esforços de diferentes instituições que tentam promover a formação de capital social encontra respaldo científico para empreender esforços visando à formação de redes duráveis de relações, capazes de gerar retornos tangíveis e intangíveis aos agentes envolvidos.

A utilização da obra de Bourdieu como referencial para o nosso trabalho não significa reduzir a interpretação da ocorrência e do fomento à formação do capital social a uma perspectiva utilitarista e restrita a questões econômicas. Como escrevemos, Bourdieu afirma existir propriedades úteis, capazes de gerar lucros materiais, mas também simbólicos, incluindo motivações e atributos dos agentes possuidores de capital social, como prestígio, honra. Costa e Costa (2005), afirmam que a ação cooperativa é mais efetiva onde existam instituições e relações sociais que contem com a confiança da população. Para os autores, os atores sociais aproveitariam melhor os benefícios do capital social ali onde existissem estes dispositivos institucionais.

\section{DELINEAMENTO DA PESQUISA}

Esta pesquisa situa-se no âmbito das pesquisas qualitativas e está circunscrita aos níveis exploratório-descritivos. Segundo Gil (2012), as pesquisas exploratórias-descritivas têm como objetivo realizar uma aproximação a determinado fenômeno, tendo como finalidade desenvolver, esclarecer e modificar conceitos e 
ideias. Estas pesquisas geralmente utilizam-se de pesquisa bibliográfica e documental, entrevistas e estudo de caso, instrumentos de levantamento de dados e análise que utilizamos nesta pesquisa. Complementando esta fonte de evidências, outra ferramenta de recolhimento de dados utilizada foi à observação participante.

Neste estudo de caso, realizou-se a investigação de um fenômeno atual, fazendo a descrição e análise do caso da Associação dos Produtores Rurais de Estância Velha (APREV), instituição criada no ano de 2012, composta por agricultores familiares do município que dá nome a associação, cuja constituição apresenta relações fundantes com a implementação de uma política pública, o PNAE.

Nesta pesquisa foram realizadas três entrevistas junto a informantes-chave visando reconstituir o processo de formação da associação e analisar as antigas e novas relações estabelecidas entre os associados. Entendeu-se como satisfatória a amostragem, haja visto o profundo conhecimento sobre todo o fenômeno estudado pelos informantes utilizados. Outro instrumento de levantamento de informações utilizado foi a observação participante. Dois momentos específicos para a observação sistemática e consentida foram utilizados, sendo o primeiro deles a operacionalização da entrega dos alimentos através de veículo coletivo utilizado para este fim, e o segundo momento formal de observação foi durante uma reunião da APREV, oportunidade em que se pôde observar a participação, o protagonismo, as falas e as deliberações retiradas da reunião. Na pesquisa documental foram utilizados dados de documentos da associação e sobre o PNAE, em especial com informações retiradas do Livro de Atas da Associação, e fontes bibliográficas.

A análise dos dados obtidos, discussão e apontamento de resultados foram realizados através de análise de conteúdo. Marcou o artigo o diálogo com teorias e demais referências que abordam o assunto, buscando mostrar em profundidade as especificidades do caso.

\section{ANÁLISE E DISCUSSÃO DOS RESULTADOS}

Nesta seção fazemos a análise e interpretação dos dados, apresentando de forma sistemática as informações obtidas através das diferentes técnicas de pesquisa e dialogando com os referenciais teóricos já escritos na revisão bibliográfica, de modo a construir uma interpretação mais ampla e coerente. Esta seção está dividida em três itens. No primeiro deles é descrito o processo de implementação do PNAE em Estância Velha e discutido sobre suas interfaces com a criação da APREV. No segundo item é analisado o processo dinâmico, desencadeado pela fundação da APREV, de construção de agentes mais solidários e que praticam a cooperação, discutindo sobre as resistências individualistas em diálogo com teorias que analisam o comportamento humano. Por fim, no terceiro item encontra-se a discussão sobre a formação de capital social a partir da política pública do PNAE, colocando em diálogo as informações obtidas no campo e as fontes documentais com teorias que dão corpo à construção do texto.

\subsection{EXECUÇÃO DO PNAE EM ESTÂNCIA VELHA E A CRIAÇÃO DA APREV}

Segundo informações obtidas no site do FNDE (2016), a partir da Constituição Federal de 1988 "ficou assegurado o direito à alimentação escolar a todos os alunos do ensino fundamental por meio de programa suplementar de alimentação escolar a ser oferecido pelos governos federal, estaduais e municipais". Desde lá, diferentes formas de garantia da alimentação escolar foram implantadas e, a partir de 2009, passa a vigorar a Lei do PNAE, que estendeu o direito à alimentação 
escolar para toda a rede pública de educação básica, inclusive aos alunos participantes do Programa Mais Educação, e de jovens e adultos.

A Lei do PNAE foi regulamentada inicialmente pela Resolução do FNDE $n^{\circ}$ 38 de 16 julho de 2009, tendo sido revogada e substituída em 2013 pela Resolução do FNDE $n^{\circ} 26$, que definiu que o certame para a definição dos fornecedores deste segmento se daria via chamadas públicas. Mais recentemente, a Resolução $n^{\circ} 04$ do FNDE, de abril de 2015, trouxe algumas alterações, definindo que após a apresentação e aceitação da documentação de habilitação dos participantes na chamada pública, os projetos serão agrupados e selecionados segundo a seguinte ordem de prioridade: o grupo de projetos dos fornecedores locais sobre os demais grupos; o grupo de projetos dos fornecedores do território rural sobre os do estado e do País; e, por fim, o grupo de projetos de fornecedores do estado sobre os do País. Em cada grupo de projetos, segundo as abrangências territoriais e geográficas já apresentadas, será observada a seguinte ordem de prioridade para seleção:

\begin{abstract}
"I - os assentamentos de reforma agrária, as comunidades tradicionais indígenas e as comunidades quilombolas, não havendo prioridade entre estes; II - os fornecedores de gêneros alimentícios certificados como orgânicos ou agroecológicos, segundo a Lei $n^{\circ} 10.831$, de 23 de dezembro de 2003; III - os Grupos Formais (organizações produtivas detentoras de Declaração de Aptidão ao PRONAF - DAP Jurídica) sobre os Grupos Informais (agricultores familiares, detentores de Declaração de Aptidão ao PRONAF - DAP Pessoa Física, organizados em grupos) e estes sobre os Fornecedores Individuais detentores de DAP Física. (Resolução $n^{\circ}$ 04/2015 do FNDE, p. $1-2)$ "
\end{abstract}

A partir da Lei do PNAE, instituições vinculadas ao campo passaram a incentivar e organizar a participação dos agricultores familiares e dos empreendedores familiares rurais ou de suas organizações nas chamadas públicas do PNAE. No município de Estância Velha/RS, a partir da iniciativa dos agricultores, do Sindicato dos Trabalhadores Rurais (STR) e da EMATER/RS-ASCAR (Órgão oficial de extensão rural no RS), foi criada a Associação dos Produtores Rurais de Estância Velha (APREV) com o "objetivo principal de representar seus associados junto às instituições de direito público que adquirem gêneros alimentícios da agricultura familiar para a alimentação escolar ao abrigo da Lei Federal n 11.947/2009" (Livro Atas da APREV). Constituída a associação, registrada enquanto pessoa jurídica, esta, através de seus dirigentes, passou a representar seus associados na participação na Chamada Pública do PNAE da Prefeitura Municipal e a contribuir na organização da participação dos seus associados enquanto grupos informais nos certames do PNAE abertos pelas escolas estaduais localizadas no município. Segundo informações da entrevista $n^{\circ} 2$, seis reuniões foram realizadas a partir de 2011 para que a associação fosse criada. No dia 16 de maio de 2012 foi realizada a assembleia de fundação, contando com quatorze agricultores. Atualmente, a associação conta com 23 associados, sendo que 17 destes participam na comercialização da chamada pública do município.

A APREV enquadra-se em dois critérios que a colocam em condição vantajosa em relação a outros fornecedores, quais sejam a de ser um fornecedor local e a de ser um grupo formal, com Cadastro Nacional de Pessoas Jurídica (CNPJ) e Declaração de Aptidão ao Programa Nacional de Fortalecimento da Agricultura Familiar de Pessoa Jurídica (DAP Jurídica). 
Os recursos oriundos do FNDE para a alimentação escolar são direcionados para a Entidade Executora, instituição da rede pública de ensino federal, estadual e municipal para a execução do PNAE. O órgão do executivo municipal de Estância Velha responsável pelo PNAE é a Secretaria Municipal de Educação e Cultura (SEMEC), a qual publicou Chamada Pública do PNAE em 2013, ano em que iniciou a participação da APREV no fornecimento da alimentação escolar, contando com as vantagens garantidas no certame a partir da Lei 11.947/09 e da Resolução do FNDE $n^{\circ} 26 / 2013$.

Segundo registros em Livro de Atas da APREV, a existência da associação permitiu também o acesso a outros benefícios como a aquisição de um caminhão furgão refrigerado com recursos do Ministério do Desenvolvimento Social e as caixarias para transporte dos alimentos durante o processo de distribuição dos alimentos escolares para as escolas da rede pública municipal. Como o município não possui um conselho consultivo e deliberativo sobre questões rurais, a associação incorporou importante função enquanto órgão consultivo, de controle social, de reivindicação, que, resguardadas as limitações legais, tem sido o espaço para decisão sobre as questões rurais do município.

Por sua representação, a APREV proporcionou benefício a duas agricultoras associadas com a destinação de recurso de financiamento do Fundo Estadual de Apoio ao Desenvolvimento dos Pequenos Estabelecimentos Rurais (FEAPER) com $80 \%$ de subsídio às suas agroindústrias, uma delas em processo de regularização e outra já regularizada. Mais recentemente, no ano de 2017, a associação participou da seleção de cinco famílias para receberem gratuitamente o benefício de construção de um açude para cada uma delas. Como pode ser visto, a existência da associação gerou também outros benefícios para os agricultores, externalidades positivas que conferem conquistas aos agricultores, difíceis de serem alcançadas quando estes lançam-se sozinhos no mercado e na busca por construção da sua própria infraestrutura.

A realidade dos agricultores anterior ao PNAE era de comercialização de boa parcela dos seus produtos via Central de Abastecimento de Alimentos do RS (CEASA), direto a varejistas ou na Feira do Produtor Rural. Estes mercados caracterizam-se por apresentar certa instabilidade de preços e de quantidades a serem adquiridas, não existindo também garantias de que o produto será vendido. $A$ partir da Lei do PNAE, a priorização da compra dos alimentos advindos da agricultura familiar e do empreendedor familiar rural abriu um mercado próximo, de qualidade e seguro aos agricultores, permitindo o planejamento e a sustentabilidade das propriedades, como pode ser observado na fala da entrevista número 1:

“(..) a gente estava produzindo e não tinha colocação no
mercado, e isso não traz sustentabilidade na propriedade (...)
hoje, acredito que todas as propriedades nossas se fortalecem
com o PNAE, ela é a sustentabilidade da propriedade. A nossa
associação é a menina dos olhos, digamos...ela abriu portas,
com certeza, para comercializar, não exclusivamente na
merenda e na Feira, mas abriu outras possibilidades para os
colegas, vendas diretamente ao consumidor, conhecer a
qualidade do produto, tu conversar e saber de onde vem, como
ele fez, então acho que isso começou a mudar um pouquinho
dos olhos do consumidor e valorizar o que o produtor leva (...)
Trecho retirado da entrevista número 1."

Dessa forma, observa-se que a priorização da aquisição dos alimentos disponibilizados por fornecedores locais e integrados à associação com personalidade 
jurídica garantiu que os produtos fossem consumidos próximos ao local de produção, garantindo alimento fresco e saudável aos escolares que os consomem, beneficiando também os agricultores locais, que não precisam sair do município para comercializarem os seus produtos.

\subsection{O AUTO- INTERESSE E A CONSTRUÇÃO DO “ESPÍRITO" DA COOPERAÇÃO E DA SOLIDARIEDADE}

Segundo Louis Blanc, um dos precursores do cooperativismo, "a concorrência é para o povo um sistema de extermínio", no caso dos assalariados, na busca de empregos e de melhores salários, e entre agricultores familiares, na busca individual da colocação das suas mercadorias e com melhores preços (BLANC, 2002). Como identificava Blanc, a construção da ideologia individualista tem na concorrência no mercado de trabalho um importante componente, o que, no caso dos agricultores familiares, pode ser identificado na busca individual pela colocação dos seus produtos no comércio e na tentativa de comercializar pelos melhores preços, realidade que muitas vezes era frustrada e levava agricultores ao fracasso e a saída do campo.

A Lei do PNAE criou garantias da colocação dos produtos dos agricultores fornecedores a preços de mercado final, melhores do que a venda no atacado, para intermediários ou para varejistas como a maioria dos agricultores realizam. Com isso, um dos pilares do capitalismo, a livre concorrência no mercado, é limitada por uma Lei em benefício de agricultores familiares.

Segundo autores como Bourdieu (1996) e Costa e Costa (2005) o comportamento humano submete-se a condicionamentos advindos das posições dos agentes no espaço social, que inculcam um habitus unificador de um estilo de vida, ou ainda, o homo economicus atua mediado por instituições e relações sociais, e, para o destacado precursor do cooperativismo Robert Owen (1970), o homem possui seu caráter formado pela organização que encontra desde o seu nascimento. Estas elaborações destoam da compreensão que preconiza que os indivíduos naturalmente são guiados pelo auto-interesse, são individualistas e egoístas.

Segundo os entrevistados 1 e 2, é muito presente o individualismo entre alguns associados. Segundo eles, esta realidade pode ser evidenciada no fato de que mesmo existindo um caminhão da APREV disponível e gratuito para fazer a entrega dos alimentos nas escolas, um agricultor optou por fazer a entrega com seu próprio caminhão a partir de desentendimentos entre os associados.

Quando os interesses do conjunto dos associados estão em questão, como a barganha de preços junto à prefeitura municipal, todos os associados mostram-se coesos e reivindicam melhores preços. Segundo a entrevista número 1, é presente que entre a maioria dos associados predomina a cooperação e solidariedade, como podemos ver neste trecho: "eu acredito que $70 \%$ dos nossos colegas estariam dispostos...têm o mesmo objetivo, têm a mesma visão, de fortalecer a associação, de correr atrás de novas oportunidades (...)". As falas dos entrevistados dão conta de que novos vínculos e relações foram criados a partir da criação da associação que foi estimulada pelo PNAE, o que aproximou e fortaleceu os agricultores, demonstrando que a criação de novas instituições promove a constituição de laços capazes de construir vínculos de cooperação e coloca em questão o axioma do capitalismo que preconiza a inexorabilidade existencial dos indivíduos enquanto individualistas.

Segundo Bourdieu (1996), "a cada classe de posições corresponde uma classe de habitus (ou de gostos) (...) e, pela intermediação desses habitus e de suas capacidades geradoras, um conjunto sistemático de bens e de propriedades, vinculadas entre si por uma afinidade de estilo". Podemos dizer que as posições de proximidade social, econômica e cultural colocam os agricultores que se associaram 
na APREV numa posição próxima no espaço social, reforçando um habitus social, cujos condicionamentos sociais se retraduzem num conjunto de comportamentos, vínculos e, mesmo que nem sempre motivados por definições completamente racionais, num conjunto de gostos, percepções e formas de pensar e agir.

Podemos falar em relativa proximidade entre os associados na APREV, pois mesmo em se tratando de agricultores do município, existe certa dispersão geográfica das suas moradias, existem diferenças étnicas e registram-se sensíveis diferenças econômicas entre alguns associados. Contudo, isso não impede que falemos num habitus dos agricultores sócios na APREV, que se agrupam na associação, no STR, no grupo de feirantes, e, por isto, manifestam gostos, afinidades, ações e proximidade nos seus objetivos, nos "lucros/benefícios" que podem ser obtidos por associarem-se a APREV.

A constituição ou consolidação de ideias, valores, atitudes, normas de cooperação e solidariedade dependem de um processo de construção educativa para esta prática. Esta percepção está presente na fala do entrevistado número 2, segundo o qual para superar o individualismo é necessário criar um "espírito cooperativista" que se constrói desde a escola, buscando construir uma nova geração, pois "no cooperativismo... cada um faz a sua parte, doa a si para que o outro tenha alguma coisa, é um conjunto, uma cooperativa, como já diz o nome".

Algumas afirmações retiradas das entrevistas número 1 e 2 demonstram uma forte presença individualista entre alguns associados, o que converge com as elaborações de Schneider (2003), que identifica no mundo capitalista o estímulo a comportamentos individualistas. Para este autor a educação cooperativista é vital para a construção associativista e cooperativista, pois um homem solidário, participativo e que pratique a cooperação necessita ser construído. A construção associativa e cooperativa já é um processo educacional, pois é necessária a convergência, o entendimento, a mediação, a colaboração e o empenho em prol do conjunto, contudo, são necessários processos focados na construção pedagógica que visa a construção de agentes solidários e empenhados na cooperação, o que demanda esforços unicamente direcionados para este fim.

\subsection{O ELO (CAPITAL SOCIAL) CRIADO ATRAVÉS DO PNAE}

Conforme já escrevemos anteriormente, para Pinho (1977) e Drimer e Drimer (1981), o autor Louis Blanc já reivindicava o apoio do Estado para a constituição de organizações associativas que ele chamava de fábrica social. $\mathrm{O}$ apoio se daria na concessão de empréstimo e também dirigindo a empresa até que os associados se conhecessem e pudessem se autogestionar.

Desde os anos em que precursores do cooperativismo preconizaram a criação de associações contando com o apoio Estatal, ou ainda, desde os anos em que experiências como a dos Pioneiros de Rochdale foram criadas, o Estado e a sociedade passaram por mudanças. O Estado tornou-se mais permeável a pressões de grupos sociais e políticos, como as cooperativas e associações, e a sociedade civil criou inúmeras experiências de associações e cooperativas de produção, industrialização, serviços, crédito, comercialização, entre outras, que aglutinam milhares e milhões de sócios. Com isso, tornou-se possível a criação de formas de incentivo às associações e cooperativas pelo Estado, exemplo disso, é a experiência das vantagens competitivas criadas pela política pública do PNAE a fornecedores locais e a grupos formais (com CNPJ) como a APREV.

A Lei do PNAE criou vantagens competitivas, resguardou mercado e estimulou a organização dos agricultores familiares, o que segundo os registros em 
Ata de fundação da APREV e a percepção dos entrevistados, motivou a organização da associação, que foi impulsionada pelo STR, por alguns agricultores que vieram a se tornar sócios e pela EMATER/RS-ASCAR, sendo que a intervenção desta última instituição já constitui um incentivo do poder público à formação de grupos. A realidade anterior à criação da associação, segundo o entrevistado número 2, era que nem todos os agricultores que viriam a formar a associação estavam filiados no sindicato, uns participavam na feira do produtor rural e alguns compartilhavam conhecimentos e praticavam a ajuda mútua.

Segundo a entrevista número 3 , as atividades produtivas desenvolvidas pelos associados também são diversificadas, onde alguns produzem hortifrutigranjeiros, outros trabalham com a produção agroindustrial de produtos de origem animal, outros de produtos de origem vegetal. A percepção de Bourdieu (1998) do capital social enquanto recurso potencial pode estar contido nas relações mantidas entre os associados antes da criação da associação, pois existia um "interconhecimento e interreconhecimento" entre alguns agricultores, contudo, nem todos se conheciam. Sendo assim, um importante fator aglutinador dos agricultores fundadores da associação e dos que vieram a se somar a esta, foi desempenhado pelas organizações sociais impulsionadoras do grupo.

De recurso potencial, a constituição da APREV "institucionalizou" o "grupo", cujo conjunto de agentes possui afinidades e proximidades culturais, sociais, geográficas, simbólicas e econômicas, consolidando ou constituindo ligações que podem ser permanentes e úteis aos associados e a comunidade. Esta percepção pode ser identificada na entrevista número 1, cuja transcrição trazemos abaixo:

\begin{abstract}
"Eu vim a conhecer outros colegas produtores através da associação. Eu acho que ela te deu uma visão melhor até da nossa agricultura, do que os nossos colegas produzem, do que eles podem vir a produzir. Então eu acho que abriu essa porta a associação, ela deu um elo entre os colegas produtores. [...] A associação...deu um elo mais forte entre os produtores do município...e eu vejo como um elo da gente conseguir se fortalecer pra crescer mais a associação, de abrir mais portas pra todos nós associados conseguir expandir com os nossos produtos[...] Trecho da entrevista $\mathrm{n}^{\circ} 01 . "$
\end{abstract}

Segundo as entrevistas número 2 e 3 , outras instituições também foram fortalecidas a partir da criação da APREV, como o sindicato, em que associados filiaram-se ao STR, as agroindústrias e a Feira do Produtor Rural, sendo que a partir da associação aproximaram-se os vínculos que permitiram que outros membros da APREV viessem a fazer parte da Feira, também contribuindo para que esta passasse a ser aberta duas vezes por semana e não mais somente aos sábados, como ocorria desde a sua fundação, há 17 anos. A partir da maior aproximação entre os associados e os órgãos de extensão, novas propostas de assistência técnica e extensão rural passaram a atender parcela dos associados, o que pode ser verificado na participação dos associados na Chamada Pública da Agroecologia, trabalho que tem o objetivo de contribuir para que os agricultores produzam de forma mais sustentável e caminhem no sentido de produzir de forma agroecológica.

A partir da nossa observação, identificamos outros "lucros" que o pertencimento à APREV proporciona aos seus associados que estão na base da solidariedade que justifica a existência deste grupo. Lucros simbólicos como o prestígio de ocupar posições de destaque na diretoria da associação, lucros materiais como divulgação dos produtos produzidos pelos associados e as demais vantagens que o pertencimento a associação proporcionam a partir das relações externas da 
associação, como o acesso a crédito subsidiado, representação das reivindicações dos agricultores junto a órgãos públicos, acesso à assistência técnica, entre outros. Os agricultores que se associam sem busca de benefício imediato através da comercialização via PNAE, motivo fundante da APREV, mostra que as motivações para se estabelecerem vínculos nem sempre buscam ganhos materiais em ser sócio na APREV, o que novamente mostra relativa incongruência entre o axioma capitalista do indivíduo maximizador e egoísta.

Conforme escrevemos, a constituição da APREV aproximou e consolidou relações, contudo é perceptível que a constituição ou aprofundamento dos vínculos solidários também carregam consigo atitudes interessadas, os "lucros" materiais e simbólicos na concepção Bourdieana, o que também é possível de ser reconhecido nas falas dos entrevistados e através da observação de episódios ocorridos na jovem associação. Segundo a entrevista número 1, é vital para a existência da associação aquilo que the foi o elemento fundante, a representação dos associados junto às instituições de direito público responsáveis pelas compras institucionais do PNAE. Segundo a entrevista, certamente a APREV deixaria de existir caso o PNAE acabasse, o que evidencia que o lucro, nesta situação objetivamente econômico, está na base do que justifica para os associados a sua necessidade de estar vinculado à APREV. Através da nossa observação também foi possível identificar que o que mais motiva os associados a se unirem enquanto grupo é quando estão barganhando preço para os seus alimentos junto a Prefeitura Municipal.

Indo ao encontro da perspectiva Bourdieniana quanto ao Capital Social, reconhece-se a necessidade de um trabalho de construção permanente das "redes duráveis de relações". A dinâmica existente no processo de aproximação e consolidação das relações entre os associados na APREV mostram que é imprescindível o esforço de manutenção das relações visando torná-las duradouras e a ampliar os "lucros" que podem ser garantidos a partir destas, pois os agricultores familiares estão imersos num espaço social capitalista que pretende dar a parecer que os lucros materiais ou simbólicos são fruto somente do esforço, do talento e da capacidade de sobressair-se individualmente, adotando condutas guiadas pelo autointeresse e pelo egoísmo.

\section{CONSIDERAÇÕES FINAIS}

A partir das diferentes técnicas de pesquisa que foram utilizadas podemos observar as nuances do processo de construção de "redes duráveis de relações". A irredutibilidade da manifestação de comportamentos individualistas é explicável pelo espaço social capitalista em que vivemos. Nesse sentido, se não há como considerar fora deste espaço social os membros de grupos como a APREV, podemos afirmar que se formaram laços de solidariedade e cooperação necessários ao funcionamento da associação, aproximando ou consolidando relações já existentes. Também podemos afirmar que as teorias de Bourdieu, que afirmam que os lucros auferidos pela vinculação a um grupo estão na base da solidariedade que o torna possível, encontram respaldo na realidade encontrada, pois para que a associação exista e persista são consideradas vitais as vantagens que ela proporciona aos seus associados.

O estímulo de políticas públicas para a formação de grupos é um importante instrumento de construção de laços de solidariedade e cooperação, criando ou fortalecendo o capital social que repercute na garantia de benefícios aos membros de uma associação. Os benefícios ao grupo diretamente envolvido estão expressos, no caso da APREV, na viabilização do acesso ao PNAE, e paralelamente, no acesso a 
outras políticas públicas, na ajuda mútua, na criação de órgãos de representação, como a diretoria da associação que representa os seus sócios nas reivindicações junto a órgãos públicos, no acesso à assistência técnica e extensão rural, entre outros benefícios. O PNAE também serve para consolidar, reforçar e perenizar as iniciativas econômicas e de produção locais, igualmente para consolidar as lideranças e o protagonismo local. A existência da associação também traz vantagens à comunidade local, através da oferta de alimentos frescos e de agroindústrias familiares, da dinamização da economia através da circulação dos recursos em nível local, também gerando impostos para o município.

Conclusão semelhante foi encontrada por Macedo et. al. (2017), segundo o qual políticas públicas como o PNAE incentivam a organização social, que no caso da associação analisada acabou tendo uma atuação prioritária na intermediação da comercialização junto aos mercados institucionais. Contudo, os autores identificaram importantes limites na associação constituída neste caso, pois fatores como a baixa participação dos associados nos processos de decisão junto às dificuldades do gestor em perceber outras necessidades dos associados para além da comercialização via mercados institucionais, podem levar a uma desestruturação da organização constituída caso os programas governamentais acabem. Portanto, conforme já expressamos, a dinâmica do processo de construção de redes duráveis de relações requer um esforço permanente de educação cooperativa, de mediação e mobilização, de modo a consolidar a organização social, seja ela uma associação, cooperativa, ou outra forma de organização da sociedade civil.

Por fim, queremos registrar as limitações deste estudo, que, por exemplo, não avançou no sentido de identificar a capacidade dos vínculos criados ou consolidados a partir da criação do grupo estudado tornarem-se duradouros, o que seria relevante. A continuidade deste estudo demanda conhecer, com um maior lastro de informações, a perspectiva de futuro dos membros da associação, bem como, analisar com maior profundidade as motivações que levam aos desacordos entre os associados. Estas limitações podem animar a continuidade dos estudos, seja da nossa parte ou de outros pesquisadores que possam se interessar pelo tema.

\section{REFERÊNCIAS}

BIANCHI, A. M; SANTOS, A. T. L. A. Adam Smith: filósofo e economista. São Leopoldo: Cadernos IHU Ideias - UNISINOS, ano 3, $n^{\circ}$ 35, 2005.

BLANC, L. Organização do trabalho. In: TEIXEIRA, A. (Org.). Utópicos, heréticos e malditos: os precursores do pensamento social de nossa época. Rio de Janeiro: Record, 2002.

BOURDIEU, P. Razões práticas: sobre a teoria da ação. 9. ed. Campinas, SP: Papirus, 1996.

BOURDIEU, P. O capital social: notas provisórias. In: NOGUEIRA, M. A; CATANI, A. (Org.) Escritos de educação. Petrópolis, RJ: Vozes, 1998.

BRASIL. Fundo Nacional de Desenvolvimento da Educação. Resolução Nº4/2015: Aquisição de produtos da agricultura familiar para a alimentação escolar. Disponível em: <http://www.fnde.gov.br>. Acesso em: 01 de Jul. 2017

BRASIL. Fundo Nacional De Desenvolvimento Da Educação. Resolução N 26/2013. Altera artigos da Resolução $\mathrm{N}^{\circ} 26 / 2013$, referente à forma de seleção de projetos no 
âmbito do PNAE. Disponível em: <http://www.fnde.gov.br/programas/alimentacaoescolar/alimentacao-escolar-legislacao?limitstart=0>. Acesso em: 06 de Jul. 2016

BRASIL. Lei $n^{\circ}$ 11.947/2009. Institui o Programa Nacional de Alimentação Escolar. Disponível em: <http://www.fnde.gov.br>. Acesso em: 12 de Dez. 2015

CORREA, S. M. de S. (org). Migração e a (re)construção do capital social. In: Capital social e desenvolvimento regional. Santa Cruz do Sul: EDUNISC, 2003.

COSTA, A. B; COSTA, B. M. Cooperação e capital social em arranjos produtivos locais. Disponível em: <www.anpec.org.br/encontro2005/artigos/A05A113.pdf> Acesso em: 13 de Fev. 2016

DRIMER, A. K.; DRIMER, B. Las cooperativas: fundamentos, história, doutrina Buenos Aires: Intercoop, 1973.

EVANS, P. Autonomia e parceria: estados e transformação industrial. Rio de Janeiro: Editora UFRJ, 2004.

GIL, A.C. Métodos e técnicas de pesquisa social. 6. ed. São Paulo: Atlas, 2012.

HUNT, E. K; LAUTZENHEIZER, M. História do pensamento econômico. 3. ed. Rio de Janeiro: Elsevier, 2013.

GRISA, C; SCHNEIDER, S. Três gerações de políticas públicas para a agricultura familiar e formas de interação entre sociedade e Estado no Brasil. In: GRISA, C; SCHNEIDER, S. Políticas públicas de desenvolvimento rural no Brasil. Porto Alegre: Editora da UFRGS, 2015.

MACEDO, A. C; MEIRA, B. C; LOPES JUNIOR, E. C. A; AGÁPTO, J. P; BORSATTO, R. S. Os limites de políticas públicas voltadas para agricultura familiar em promover organização social: o caso do assentamento 23 de Maio. Extensão Rural, v. 24, n. 2, p. 102-117, 2017.

OWEN, R. O livro do novo mundo moral. In: TEIXEIRA, A. (Org.). Utópicos, heréticos e malditos: os precursores do pensamento social de nossa época. Rio de Janeiro: Record, 2002.

PAULANI, L. M. A (anti) filosofia de Karl Marx. Cadernos IHU - UNISINOS, a. 3, n. 41, 2005.

PINHO, D. B. O embasamento teórico-doutrinário da atividade cooperativista. São Paulo: Saraiva, 1977.

SCHNEIDER, J. O. A doutrina do cooperativismo: análise do alcance, do sentido e da atualidade dos seus valores, princípios e normas nos tempos atuais. Cadernos Gestão Social - RGS, v. 3, n. 2, p. 251-273, 2012.

SCHNEIDER, J. O. Pressupostos da educação cooperativa: a visão de sistematizadores da doutrina do cooperativismo. In: SCHNEIDER, J. O. (Org.). Educação cooperativa e suas práticas. São Leopoldo: Editora UNISINOS, 2003. 